Transport and Communications Science Journal

\title{
THE IMPACT OF LEADERSHIP BEHAVIOR ON EFFICIENCY OF THE PUBLIC INVESTMENT MANAGEMENT OF ROAD INFRASTRUCTURE: THE CASE OF VIETNAM
}

\author{
Nguyen Luong Hai \\ University of Transport and Communications, No 3 Cau Giay Street, Hanoi, Vietnam
}

\author{
ARTICLE INFO \\ TYPE: Research Article \\ Received: 3/1/2020 \\ Revised: $24 / 2 / 2020$ \\ Accepted: 25/2/2020 \\ Published online: 28/5/2020 \\ https://doi.org/10.25073/tcsj.71.4.2 \\ * Corresponding author \\ Email: hainl@utc.edu.vn
}

\begin{abstract}
Leadership behavior is one of the fundamental functions of management principles, especially meaningful to the public management in terms of road infrastructure development in the context of scarce capital and complicate investment implementation as well. The article is aimed to clarify the impact of leadership behaviors on public management efficiency in the context of road infrastructure development in Vietnam. Through a linear regression analysis, the results have synthesized the critical leadership behaviors and figured out factors related to authority assignment, communication encouragement and motivation promotion, which influences significantly ( $\mathrm{p}<<0.05$ ) to the management performance (MP). Research results contribute significantly to both knowledge-body and practices of public management and sustainability of road infrastructure development in Vietnam.
\end{abstract}

Keywords: leadership behavior, public management, construction investment, road infrastructure

(C) 2020 University of Transport and Communication

\section{INTRODUCTION}

The efficient management of public road infrastructure investment helps developing transport network, meeting the economic development's needs as a whole. In which, the leadership behaviour is an important function to be implemented over the public management functions, contributing to the successful implementation of the investment plan and enhancing the management performance[1]. In practice of Vietnam, the leadership implemented has been 
decentralized under the regulations on the plan and the decentralization in public administrative management. However, the value of the leading implementation has been confronted with a number of problems. There are insufficient synchronization, unclear decisions made, overlapping decision-making, and non-attached responsibility over the course of public management delivery. The leadership behaviour at various management levels is occasionally inconsistent; in practice, the heterogeneity in directing the implementation of the investment plan between central and local agencies is reported [2]. As a result, coordination between all levels and sectors has been inadequate, leading to the difficulty in the implementation such as project delay and adjusting the investment scale and objectives. The leading function, on the one hand, needs closely ensuing the executed plan, which must be consistent with the situation and practical requirements, creating unity and coherence throughout the public works implementation process.

In addition, public works' clients and local governments are responsible for registering the demand and annual investment capital plan with superior agencies and Ministry of Transport., who are responsible for synthesizing the needs of those registrations of the investment plans, scheduling registration of the capital demand, allocating capital, and submitting these plans for approving by Ministry of Finance. Therefore, the leadership implemented is conducted at all management levels, which needs a clear coordination and decentralization.

However, the practice of leading implementation in the investment development of road infrastructure system in Vietnam indicates that: (1) The leading activities have potential effect on the quality of entire the public management process [3]; and (2) assessing criteria as well as level influence of the leading activities have yet been reviewed and empirically estimated. Hence, it is significant to assess the importance of the leading function on the success of public management within road infrastructure investment, which is expected to contribute improving mechanisms, policies and implementing synchronous approach for ensuring the successful objectives of the public management. Within the scope of this study, different aspects of the leadership behaviour were to be considered. In addition, this study was to adopt quantitative analysis to measure the impact of leadership behaviours on the effectiveness of the public investment management of road infrastructure development in Vietnam.

\section{MATERIALS AND METHODS}

\subsection{Hypotheses development}

In order to better assess the status of the leading function in the public management activities of road infrastructure investment in Vietnam, criteria are considered based on the body knowledge of management principles[4], Accordingly, the leading function or leadership behaviour is contextually examined within the practice of public management activities of road infrastructure development. Therefore, the examining criteria for leadership behaviour are expected to clarify the following practices [4-7]: The ability of decisionmaking, building accountability in implementation, communication, obligation and motivation for stakeholders in effectively implementing. As a result, 5 attributes were compiled and suggested for measurement as leadership behaviour factors (Table 1): 
Table 1. Attributes of leadership behavior.

ID Attributes

Description

\section{Leaders are authorized to make a number of decisions by themselves. \\ 1 D1 Leader need to identify the skills of each employee, and assign duties to

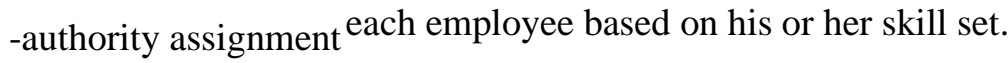 \\ D2 A leader is responsible for both the successes and failures of his or her 2 -Responsibility team in investment management. The leader is willing to accept blame orientation when something goes wrong. D3 them in order to achieving investment objectives and plan; also, clearly and \\ 3 -Communication encouragement to specific tasks.}

4

D4 Leaders are able to ensure their subordinates' accountability over the -Duty clarification course of investment plan. to reaching the investment objectives. Subordinates and stakeholders are

$5 \quad$-Motivation promotion always supported and encouraged to maintain a high level of motivation over the course of the investment plan.

In addition, the evaluating criterion of overall satisfaction [8] on effectiveness of public management was suggested as the dependent variable in the research model. As such, the research model and hypothesis were developed specifically: leadership behaviours have a statistically significant effect on public management efficiency within road infrastructure investment.

\subsection{Measures and data collection}

First of all, the collected data will be statistically descripted, followed by the linear regression method performed, which helps to analyse the prognostic model between independent variables and dependent variable. This traditional method is appropriate with analytical samples without a large number of variables, and is implemented in SPSS software.

Based on the research model developed, it can be noted that the survey sample for variables in the research model is to be designed including 05 contents for independent variables (Table 1) and content for the dependent variable; as a total of 6 surveyed contents for all variables in the research model. The survey items were divided into two parts. First, respondents were asked to clarify their demographic characteristics and describe the features 
of their professionals, whereas the second part aimed to collect data on behavioural attributes and overall satisfaction aspects. The respondents were requested to specify their experience with the public management on a five-point Likert scale of 1 (strongly disagree/not at all satisfied) to 5 (strongly agree/extremely satisfied).

Based on the literature and discussions with key stakeholders, case-specific data were collected by practitioners involved in public management of road infrastructure investment in Vietnam who served as managers and senior officers for public agencies related road infrastructure investment (21\%), clients (39\%), control departments (Public inspection and audit units) (18\%) and academia (22\%). This approach was also validated by consultations for a pilot study, which helped to clarify that those targeted respondents with responsibilities as team leaders or managing directors were the most appropriate survey respondents. As a result, official questionnaires were distributed to 199 randomly targeted participants who were asked to answer specific survey inquiries based on the participants' experiences with the most recently relevant public management activities. A final sample of 139 valid responses was obtained for investigation which is valid as the minimum number of survey samples proposed by Sekara [9].

\section{RESULTS AND DISCUSSION}

\subsection{Description analyses}

The descriptive analysis of leadership behaviours is shown in Table 2. The results indicate that the assessments of those behaviours are above the threshold of medium. This finding shows that the leadership behaviours of public management of road infrastructure investment have not been excessively poor. However, it should be conveyed more obviously, creating a change in the efficiency and quality of the public management.

Table 2. Description of leadership behaviour's attitudes.

\begin{tabular}{ccccccc}
\hline ID & Criteria & $\mathbf{N}$ & Mean & Std. Deviation & Minimum & Maximum \\
\hline 1 & D1 & 139 & 3.4245 & 0.77064 & 1.00 & 5.00 \\
\hline 2 & D2 & 139 & 3.3669 & 0.78152 & 1.00 & 5.00 \\
\hline 3 & D3 & 139 & 3.4173 & 0.70092 & 2.00 & 5.00 \\
\hline 4 & D4 & 139 & 3.3453 & 0.70928 & 2.00 & 5.00 \\
\hline 5 & D5 & 139 & 3.0216 & 0.76582 & 2.00 & 5.00 \\
\hline
\end{tabular}

On the other hand, analysing the different perceptions of various target groups in terms of the behavioural criteria is shown in Table 3. The results show that there is no statistically significant difference between the surveyed groups for the behavioural leadership. This may well explain the unity of the parties in assessing the importance of directing behaviours implemented within public investment management. 
Transport and Communications Science Journal, Vol. 71, Issue 4 (05/2020), 328-335

Table 3. Analysis of variance in regard to behavioural attributes.

\begin{tabular}{lccccc}
\hline Criteria & D1 & \multicolumn{1}{c}{ D2 } & \multicolumn{1}{c}{ D3 } & \multicolumn{1}{c}{ D4 } & \multicolumn{1}{c}{ D5 } \\
\hline Mann-Whitney U & 389.000 & 371.500 & 411.500 & 424.000 & 382.500 \\
\hline Wilcoxon W & 542.000 & 524.500 & 564.500 & 577.000 & 535.500 \\
\hline Z & -1.354 & -1.577 & -1.061 & -0.866 & -1.442 \\
\hline Asymp. Sig. (2-tailed) & 0.176 & 0.115 & 0.289 & 0.386 & 0.149 \\
\hline
\end{tabular}

\subsection{Linear regression analyses}

Before performing regression analysis, correlation analysis was conducted to test the correlation between the independent variables and the dependent variables in the prognostic model. The analytical results (Table 4) show that all the evaluation criteria of leadership behaviour have a statistically significant correlation $(p<0.01)$ with the evaluating criterion of the public investment effectiveness (MP). This result, on the one hand, shows the appropriateness of proposing those evaluation criteria in the research model; on the other hand, the correlation level also shows evidently the impact of independent variables into dependent variables.

Table 4. Correlations analyses.

\begin{tabular}{clccccc}
\hline & Statistics & D1 & D2 & D3 & D4 & D5 \\
\hline \multirow{3}{*}{ MP } & Pearson Correlation & $0.494^{* *}$ & $0.487^{* * *}$ & $0.557^{* * *}$ & $0.456^{* *}$ & $0.497^{* *}$ \\
\cline { 2 - 7 } & Sig. (2-tailed) & 0.000 & 0.000 & 0.000 & 0.000 & 0.000 \\
\cline { 2 - 7 } & Covariance & 0.290 & 0.290 & 0.297 & 0.246 & 0.290 \\
\cline { 2 - 7 } & $\mathrm{N}$ & 139 & 139 & 139 & 139 & 139 \\
\hline
\end{tabular}

The results of linear regression analysis are shown in table 5 and table 6 . This shows the best model proposed by the "stepwise" algorithm that is based on the selection of independent variables in explaining the difference of the dependent variable.

Table 5. Model summary.

\begin{tabular}{lllllll} 
Model & R & _Square & $\begin{array}{l}\text { Adjusted } \\
\text { R_Square }\end{array}$ & $\begin{array}{l}\text { Std. Error of } \\
\text { the Estimate }\end{array}$ & F test & Sig. \\
\hline 1 & 0.654 & 0.427 & 0.415 & 0.58256 & 33.576 & 0.000 \\
\hline
\end{tabular}

Specifically, the selected model indicates three independent variables including 
authority assignment (D1), communication encouragement (D3) and motivation promotion (D5) having a statistically significant effect $(\mathrm{p}<0.05)$ on the dependent variable, the effectiveness of public construction investment management (MP). As a result, it enables to explain $41.5 \%$ of the variation of MP, which reflects a statistically significant level (F-test with $p<0.001$ ).

Table 6. Linear regression model selection.

\begin{tabular}{|c|c|c|c|c|c|c|c|}
\hline \multirow[t]{2}{*}{ Model } & \multicolumn{2}{|c|}{$\begin{array}{l}\text { Unstandardized } \\
\text { Coefficients }\end{array}$} & \multirow[t]{2}{*}{$\begin{array}{l}\text { Standardized } \\
\text { Coefficients }\end{array}$} & \multirow[b]{2}{*}{ t-test } & \multirow[b]{2}{*}{ Sig. } & \multicolumn{2}{|c|}{$\begin{array}{l}\text { Collinearity } \\
\text { Statistics }\end{array}$} \\
\hline & B & $\begin{array}{l}\text { Std. } \\
\text { Error }\end{array}$ & & & & $\begin{array}{l}\text { Toleran } \\
\text { ce }\end{array}$ & VIF \\
\hline Constant & 0.205 & 0.284 & & 0.722 & 0.472 & & \\
\hline D1 & 0.259 & 0.073 & 0.262 & 3.522 & 0.001 & 0.767 & 1.304 \\
\hline D3 & 0.339 & 0.087 & 0.312 & 3.891 & 0.000 & 0.660 & 1.514 \\
\hline D5 & 0.249 & 0.076 & 0.250 & 3.289 & 0.001 & 0.734 & 1.362 \\
\hline
\end{tabular}

Analyses of residuals are widely used to test the assumptions of the regression. As a result, the plots of the residuals were shown a bell-shaped distribution of Histogram of standardized residuals, indicating that the assumption of normality has not been violated.

Firstly, the findings from selected model have confirmed the research hypothesis: authority assignment in the implemented plan has a positively significant impact $(p<0.0001)$ on the efficiency of the public investment management. In fact, building a mechanism for empowering leaders plays a vital role fulfilling their responsibility as well as giving authority to the managerial functions. As such, the responsibilities of each unit and/or individuals involved in ensuring the implementation of the plan are feasible and effective, in order to achieve the planned objectives.

Secondly, the analytical results reinforce the research hypothesis: communication encouragement contributes a positively significant role $(p<0.0001)$ to the effectiveness of public investment management. Communication and connection between the relevant stakeholders during public management delivery are very important to help opening up information flow and clarifying obstacles related. In addition, clear administrative procedures help parties understanding each other better, which is the basis of cooperation and commitment to each other for the common management goals. If there is no effective communication between parties, it will not only create a bottleneck in management, but also a sufficient motivation to improve managerial performance, which is the cause of reduced efficiency of managerial functions.

Third, the analytical results accept the research hypothesis: the motivation promotion indicates a significant effect $(\mathrm{p}<0.001)$ on the effectiveness of public investment management. It is essential to create incentives for the relevant stakeholders within the public management process. The external motivations (in terms of material encouragement and 
reward) and internal motivation (in terms of value and working environment) are always a prerequisite for each individual or organization to consider level of dedication to the common goals.

On the other hand, the prognostic model also shows the variables including responsibility orientation and duty clarification which have not significant effect ( $>>0.05)$ on MP dependent variable. This result may not well explain the principles of management and/or organizational behaviour, but it can be seen as a contextual situation the public management within road infrastructure investment in Vietnam. Public investment within the field of road infrastructure construction has been performed without an assurance of clear stakeholders' responsibilities [10]. In fact, the lack of accountabilities clarified has created a number of problems in the managerial practices. Additionally, creating a confusing responsibility promotes a negative consequence on efficiency of process delivery in public such as bureaucratic and corruption.

\section{CONCLUSION}

The study has conducted quantitative analysis of the influence of leadership behaviors on the efficiency of public investment management in road infrastructure construction. The results have clarified scientific evidence to accept research hypothesis: independent variables related to authority asignment, communication encouragement and motivation promotion have a statistically significant impact $(\mathrm{p}<0.05)$ to the dependent variable - efficiency of the public management. The analytical results show the model that can explain $41.5 \%$ difference $($ R_square $=0.415)$ in the dependent variable.

The research results provide empirial evidence for proposing solutions in improving the effectiveness of public investment management within road infrastructure construction, particularly at project level. On the one hand, it helps to create incentives for non-public economic sectors to consider attending their involvement that share and support the public investment in developing the road infrastructure system, which is the basis for maintaining sustainable economic growth.

\section{REFERENCES}

[1]. Y. Tsai, Relationship between Organizational Culture, Leadership Behavior and Job Satisfaction, BMC Health Serv Res, 11 (2011) 98. https://doi.org/10.1186/1472-6963-11-98

[2]. L.R. Offermann, P.S.Hellmann, Culture's consequences for leadership behavior: National values in action, Journal of cross-cultural psychology, $28 \quad$ (1997) 342-351. https://doi.org/10.1177/0022022197283008

[3]. L.H. Nguyen, T. Watanabe, An Investigation of the Relationship between Project Organizational Culture and Procurement Approach of Construction Project Organizations, Int. J. Socie. Soci. Manag. Sys., 10 (2016) 50-61. https://ssms.jp/wp-content/uploads/2019/04/sms15 3292.pdf

[4]. C. Williams, Principles of management, South-Western Cengage Learning,2013.

[5]. A. Walker, Organizational behaviour in construction, John Wiley \& Sons, 2011.

[6]. A. Walker, Project management in construction, John Wiley \& Sons, 2015. 
Transport and Communications Science Journal, Vol. 71, Issue 4 (05/2020), 328-335

[7]. S. McShane, M. Von Glinow, Organizational Behavior, New York: McGraw-Hill/Irwin, 2013.

[8]. L.H. Nguyen, Relationships between Critical Factors Related to Team Behaviors and Client Satisfaction in Construction Project Organizations. Journal of Construction Engineering and Management, 145 (2019) 04019002. https://doi.org/10.1061/(ASCE)CO.1943-7862.0001620

[9]. U. Sekaran, R. Bougie, Research methods for business: A skill building approach, John Wiley \& Sons, 2016.

[10].L.H. Nguyen, T.Watanabe, The status quo and perspective for improvement of public works procurement performance in Vietnam, J. Adv. Perform. Informat. Value., 6 (2014) 22-39. https://cibw117.org/wp-content/uploads/2018/03/The-status-quo-and-perspective-for-improvement-ofpublic-works-procurement-performance-in-Vietnam-FORMATTED.pdf 